\title{
Pengertian DHCP Server
}

MUJI SETIA

175100027

Fakultas Komputer

mujisetia.student@umitra.ac.id

\begin{abstract}
Abstrak
Pada jaringan komputer yang besar konfigurasi parameter TCP/IP pada masing-masing workstation akan sngat merepotkan dan membutuhkan waktu yang sangat lama,terutama ketika parameter TCP/IP seperti alamat IP dan subnetmask memerlukan perubahan.

Dinamic Host Configuration Protokol (DHCP) adalah layanan dari server yangdigunakan untuk mengkonfigurasi secara Dinamik maupun Statis.TCP/IP host yang meminta informasi konfigurasi TCP/IP disebut DHCP Client,sedangkan TCP/IP host yang memberi Iformasi konfigurasi TCP/IP disebut DHCP server.

Konfigurasi alamat IP pada DHCP client diberikan oleh administrator jaringan pada server DHCP.dan DHCP digunakan untuk menyampaikan alamat IP tersebut yang di konfigurasi ke DHCP client.pada metode ini administrator jaringan akan memberikan alamat IP pada host tertentu dari DHCP server.yang artinya alamat IP yang sama akan selalu diberikan ke DDdHCP client tertentu.
\end{abstract}


$\stackrel{\text { Fakultas Komputer }}{\stackrel{*^{*} *}{*} \text { TUGAS } 1 \text { - } 88675543}$

Muji Setia 


\section{A. PENDAHULUAN}

Pada jaringan komputer yang besar konfigurasi parameter TCP/IP pada masingmasing workstation akan sngat merepotkan dan membutuhkan waktu yang sangat lama,terutama ketika parameter TCP/IP seperti alamat IP dan subnetmask memerlukan perubahan.

Dinamic Host Configuration Protokol (DHCP) adalah layanan dari server yangdigunakan untuk mengkonfigurasi secara Dinamik maupun Statis.TCP/IP host yang meminta informasi konfigurasi TCP/IP disebut DHCP Client,sedangkan TCP/IP host yang memberi Iformasi konfigurasi TCP/IP disebut DHCP server.

Konfigurasi alamat IP pada DHCP client diberikan oleh administrator jaringan pada server DHCP.dan DHCP digunakan untuk menyampaikan alamat IP tersebut yang di konfigurasi ke DHCP client.pada metode ini administrator jaringan akan memberikan alamat IP pada host tertentu dari DHCP server.yang artinya alamat IP yang sama akan selalu diberikan ke DDdHCP client tertentu. 


\section{B}

\section{- PEMBAHASAN / STUDI KASUS}

DHCP (Dynamic Configuration Protocol) adalah layanan yang secara otomatis memberikan nomor IP kepada komputer yang memintanya. Komputer yang memberikan nomor IP disebut sebagaiDHCP server, sedangkan komputer yang meminta nomor IP disebut sebagai DHCP

Client.

Protokol yang berbasis arsitektur client/server yang dipakai untuk memudahkan pengalokasian alamat IP dalam satu jaringan. Sebuah jaringan lokal yang tidak menggunakan DHCP harus memberikan alamat IP kepada semua komputer secara manual. Jika DHCP dipasang di jaringan lokal, maka semua komputer yang tersambung di jaringan akan mendapatkan alamat IP secara otomatis dari server DHCP. Selain alamat IP, banyak parameter jaringan yang dapat diberikan oleh DHCP, seperti default gateway dan DNS server.

DHCP akan sangat membantu sekali karena semua konfigurasi jaringan bisa dilakukan dari sebuah komputer yang berlaku sebagai DHCP Server, sehingga client yang terhubung pada jaringan tidak perlu untuk mengkonfigurasikannya secara manual. Karena DHCP merupakan sebuah protokol yang menggunakan arsitektur client/server, maka dalam DHCP terdapat dua pihak yang terlibat, yakni DHCP Server dan DHCP Client.

DHCP server merupakan sebuah mesin yang menjalankan layanan yang dapat "menyewakan" alamat IP dan informasi TCP/IP lainnya kepada semua klien yang memintanya. Beberapa sistem operasi jaringan seperti Windows NT

Server, Windows 2000 Server, Windows Server 2003, atauGNU/Linux memiliki layanan seperti ini.
DHCP client merupakan mesin klien yang menjalankan perangkat lunak klien DHCP yang memungkinkan mereka untuk dapat berkomunikasi dengan DHCP Server.

Sebagian besar sistem operasi klien jaringan (Windows NT Workstation, Windows 2000 Professional, Windows XP, Windows Vista, atau GNU/Linux) memiliki perangkat lunak seperti ini.

DHCP server umumnya memiliki sekumpulan alamat yang diizinkan untuk didistribusikan kepada klien, yang disebut sebagai DHCP Pool. Setiap klien kemudian akan menyewa alamat IP dari DHCP Pool ini untuk waktu yang ditentukan oleh DHCP, biasanya hingga beberapa hari. Manakala waktu penyewaan alamat IP tersebut habis masanya, klien akan meminta kepada server untuk memberikan alamat IP yang baru atau memperpanjangnya.

DHCP Client akan mencoba untuk mendapatkan "penyewaan" alamat IP dari sebuah DHCP server dalam proses empat langkah berikut:

DHCPDISCOVER: DHCP client akan menyebarkan request secara broadcast untuk mencari DHCP Server yang aktif.

DHCPOFFER: Setelah DHCP Server mendengar broadcast dari DHCP Client, DHCP server kemudian menawarkan sebuah alamat kepada DHCP client.

DHCPREQUEST: Client meminta DCHP server untuk menyewakan alamat IP dari salah satu alamat yang tersedia dalam DHCP Pool pada DHCP Server yang bersangkutan. DHCPACK: DHCP server akan merespons permintaan dari klien dengan mengirimkan paketacknowledgment. Kemudian, DHCP Server akan menetapkan sebuah alamat (dan konfigurasiTCP/IP lainnya) kepada klien, dan memperbarui basis data database miliknya. Klien selanjutnya akan memulai proses binding dengan tumpukan protokol TCP/IP dan karena telah memiliki alamat IP, klien pun dapat memulai komunikasi jaringan. 
Empat tahap di atas hanya berlaku bagi klien yang belum memiliki alamat. Untuk klien yang sebelumnya pernah meminta alamat kepada DHCP server yang sama, hanya tahap 3 dan tahap 4 yang dilakukan, yakni tahap pembaruan alamat (address renewal), yang jelas lebih cepat prosesnya.

Berbeda dengan sistem DNS yang terdistribusi, DHCP bersifat stand-alone, sehingga jika dalam sebuah jaringan terdapat beberapa DHCP server, basis data alamat IP dalam sebuah DHCP Server tidak akan direplikasi ke DHCP server lainnya. Hal ini dapat menjadi masalah jika konfigurasi antara dua DHCP server tersebut berbenturan, karena protokol IP tidak mengizinkan dua host memiliki alamat yang sama.Selain dapat menyediakan alamat dinamis kepada klien, DHCP Server juga dapat menetapkan sebuah alamat statik kepada klien, sehingga alamat klien akan tetap dari waktu ke waktu. DHCP Scope DHCP Scope adalah alamat-alamat IP yang dapat disewakan kepada DHCP client. Ini juga dapat dikonfigurasikan oleh seorang administrator dengan menggunakan peralatan konfigurasi DHCP server. Biasanya, sebuah alamat IP disewakan dalam jangka

\section{KESIMPULAN}

DHCP (Dynamic Configuration Protocol) adalah layanan yang secara otomatis memberikan nomor IP kepada komputer yang memintanya. Komputer yang memberikan nomor IP disebut sebagai DHCP server, sedangkan komputer yang meminta nomor IP disebut sebagai DHCP Client.

Dalam praktek kerjanya menggunakan dua operasi sistem yaitu LINUX dan Windows.Linux sebagai server dan Windows sebagai Client.Dalam Konfigurasinya menggunakan dua metode yaitu Random dan Fixed.

DHCP merupakan protocol yang dipakai untuk pengalokasian alamat IP dalam satu jaringan atau lebih.

Jika non DHCP, pemberian alamat IP diset secara manual satu per satu ke seluruh komputer yang terkoneksi dengan jaringan. waktu tertentu, yang disebut sebagai DHCP Lease, yang umumnya bernilai tiga hari. Informasi mengenai DHCP Scope dan alamat IP yang telah disewakan kemudian disimpan di dalam basis data DHCP dalam DHCP server. Nilai alamat-alamat IP yang dapat disewakan harus diambil dari DHCP Pool yang tersedia yang dialokasikan dalam jaringan. Kesalahan yang sering terjadi dalam konfigurasi DHCP Server adalah kesalahan dalam konfigurasi DHCP Scope.

DHCP Lease

DHCP Lease adalah batas waktu penyewaan alamat IP yang diberikan kepada DHCP client oleh DHCP Server. Umumnya, hal ini dapat dikonfigurasikan sedemikian rupa oleh seorang administrator dengan menggunakan beberapa peralatan konfigurasi (dalam Windows NT Server dapat menggunakan DHCP Manager atau dalam

Jika menggunakan DHCP, seluruh host yng tersambung di jaringan akan mendapatkan alamat IP secara otomatis dari server DHCP sehingga memudahkan administrator dalam penangan jaringan.

Selain alamat IP, banyak parameter jaringan yang dapat diberikan oleh DHCP seperti default gateway dan DNS server.

DHCP3-server adalah salah satu software support yang membantu pengalokasian alamat IP dalam system jaringan.

\section{E. DISKUSI}

Teman saya bernama syarifudin berpendapat tentang mengenai mengenai tentang DHCP server adalah Dynamic 
Host Configuration Protocol atau yang biasa dikenal dengan DHCP adalah layanan pemberian nomor IP secara otomatis yang diberikan kepada komputer-komputer yang membutuhkan. Komputer yang memberikan IP (Internet Protocol) kepada komputer yang meminta disebut dengan DHCP Server, sedangkan yang dipinjamkan sebuah nomor IP disebut dengan DHCP Client.

\section{F. REFERENCE}

https://charis23.wordpress.com/2015/09/11/setting-dhcpserver-debian/

- http://bacacoding.blogspot.co.id/2016/05/cara-

konfigurasi-dhcp-server-di-linux.html

- $\quad$ http://www.pintarkomputer.com/penjelasan-lengkapdhcp-server-dan-cara-kerjanya/ 